\title{
Is it difficult for students to lead a healthy lifestyle while attending University? A pilot study
}

\author{
M. R. Sweeney ${ }^{1}$, A. Boilson ${ }^{1}$, A. Staines ${ }^{1}$, C. Kelleher ${ }^{2}$, E. Bateman ${ }^{1}$ and J. Conlon ${ }^{1}$ \\ ${ }^{1}$ School of Nursing, Dublin City University Dublin, Republic of Ireland and ${ }^{2}$ UCD School of Public Health and Population \\ Science, University College Dublin, Dublin, Republic of Ireland
}

Several US studies have shown that propensity to weight gain amongst 'freshman students' (first-year university students) ${ }^{(1-3)}$ a common trend, with variability in weight gain ranging from two to fifteen pounds. These findings indicate that entry into the 3 rd level education system (university and colleges of higher education) may be a critical time-point in the pathway to adult overweight and obesity for some students. While several Irish studies have examined the dietary intakes and weights of Irish schoolchildren ${ }^{(4-5)}$, teenagers ${ }^{(6-7)}$ and adults $^{(4-5)}$, currently there are no comprehensive dietary intake and weight studies amongst Irish university students.

The present pilot study set out to explore whether entry into 3rd level education has any negative impact on diet, lifestyle and weight status.

The pilot study was conducted at Dublin City University (DCU). Thirty students from each of the Schools or Faculties in DCU were recruited, giving a total of 120 . After informed consent participants completed a short questionnaire exploring whether their diet, lifestyle and weight status had improved, deteriorated or remained the same since starting University. Subjects were weighed using a portable calibrated weighing scales in their bare feet with their outer clothing removed. Heights were also recorded. An equal gender mix was sought at each School or Faculty but was not always achieved. First-year students were excluded. Data were analysed by SPSS version 11 (SPSS Inc., Chicago, IL, USA).

Males represented $46.2 \%$ of the participants and $53.8 \%$ were females. The age range was $18-36$ years, overall mean age 22.05 years, males 22.69 years, females 21.50 years. The majority of participants $(80.7 \%)$ were undergraduates. Health since starting college was rated as 'less healthy' by $39.5 \%$, 'the same' by $37.8 \%$ and 'healthier' by $22.7 \%$. Weight was reported by $58 \%$ to have 'increased' since starting college, the range of weight gain being from $<3.17 \mathrm{~kg} 15.6 \%$ to $>12.7 \mathrm{~kg} 4.7 \%$ of participants. Weight was reported by $25.2 \%$ to have 'stayed the same' and $16.8 \%$ reported a 'decrease in weight'. Diet was stated to be 'less healthy' since starting college by $42.4 \%$ of participants, while $40.7 \%$ said it was the 'same' and $16.9 \%$ said it was 'healthier'. Of the participants $41.2 \%$ said that they 'exercised less' since starting college, $30.3 \%$ said they 'exercised the same' and $28.6 \%$ said they 'exercised more'. An 'increase' in alcohol intake since starting college was reported by $58.7 \%$ of respondents. It was found that $32.8 \%$ of participants were overweight, of whom $63.9 \%$ were males and $36.1 \%$ were females. Those who fell into the obese category comprised $6.4 \%$ of the sample.

These results indicate that entry into the 3rd level education system may indeed be a critical point in the pathway to a less-healthy lifestyle and diet as well as a shift in weight status towards overweight and obesity and may indicate a time-point for a strategic policy intervention. Further research is needed.

With thanks to the 'National Nutrition Surveillance Unit' in the School of Public Health \& Population Science, UCD for the use of the anthropometry equipment.

1. Delinske SS, Wilson GT. Weight gain, dietary restraint, and disordered eating in the freshman year of college. Eat Behav. 2008 Jan;(9): 82-90.

2. Racette SB, Deusinger SS, Strube MJ, et al. Changes in weight and behaviors from freshman through senior year in college. J Nutr Behav. 2008 Jan-Feb; 40(1): 39-42.

3. Jung ME, Bray SR, Martin Ginis KA. Behavior change and the freshman 15: tracking physical activity and dietary patterns in 1st-year university women. $2008 \mathrm{~J}$ Am Coll Health Mar-Apr; 56(5):523-30.

4. Friel, S., Nic Gabhainn, S. \& Kelleher, C et al. The National Lifestyle Surveys: Survey of Lifestyle, Attitudes and Nutrition (SLÁN) and the Irish Health Behavior in School-Aged children survey (HBSC). 1999 Department of Health and Children: Dublin.

5. Kelleher, C., Nic Gabhainn, S., Friel, S. et al. National Health and Lifestyle Surveys: Survey of Lifestyle, Attitudes and Nutrition (SLÁN) and the Irish Health Behavior in School-Aged children survey (HBSC). 2003 Department of Health and Children: Dublin.

6. IUNA (2001) North South Ireland Food Consumption Survey. www.iuna.net/index.php/research/northsouth-food-survey [accessed 09/07/2009].

7. IUNA (2008) National Teens' Food Survey. http://www.iuna.net/index.php/research/teen-food-survey 